\title{
Como o negro aparece? Formulações gerais sobre a presença do negro nos livros didáticos de história do Ensino Médio
}

How do black people appear? General Formulations about the black presence in history didactic books of high school

Humberto Rafael de Andrade Silva* humbertorafae15329@gmail.com

Resumo: $\mathrm{O}$ trabalho tem como objetivo analisar a iconografia relacionada à temática afrobrasileira nas dezenove coleções aprovadas pelo Plano Nacional do Livro Didático, nos anos de 2012 a 2014. Para isso, procedeu-se a catalogação das imagens em Microsoft Excel identificando seus aspectos materiais (as informações que o livro fornece da imagem) e de contexto (localização da imagem no interior da publicação, relação da imagem com o texto verbal, além de observações feitas sobre peculiaridades das coleções).

Palavras-chave: livros didáticos, imagem, história afro brasileira, relações étnico-raciais

Abstract: The objective of the study is to analyze the iconography related to Afro-Brazilian theme in nineteen collections approved by the National Plan of Didactic Book, period 2012 to 2014. In order to do so, the images were catalogued in Microsoft Excel identifying material aspects and context (such as location within the publication, relation with the verbal text, as well as observations on the peculiarities of the collections).

Keywords: didactic books, image, Afro Brazilian History, ethnic-racial relations 
Sobre a questão da história como política pública

Em nosso país, vivemos sobre um modelo de democracia representativa que garante aos cidadãos determinados bens sociais. A garantia desses, assim com a manutenção das necessidades da população nos campos essenciais, segundo Azevedo (2004, p. 5) se faz através da "materialidade da intervenção do estado", ou seja, o estado agindo para resolver determinadas demandas. Tais estratégias e métodos de ação são chamados políticas públicas. Uma das principais influências no seu estabelecimento é a demanda popular. Segundo Azevedo:

[...] as políticas públicas são definidas, implementadas, reformuladas ou desativadas com base na memória da sociedade ou do Estado em que têm lugar e que por isso guardam estreita relação com as representações sociais que cada sociedade desenvolve sobre si própria (AZEVEDO, 2004, p, $5)$.

O estabelecimento de políticas públicas estaria norteado tanto pela correção de problemas reivindicados pela população, quanto pelas metas que a mesma estabelece como um futuro possível. Dentro do campo das políticas públicas, vamos abordar a histórica demanda pela valorização da diversidade étnico-racial no Brasil.

A partir do final da segunda metade do século XX conseguimos ver uma mobilização de maior vulto das instâncias da sociedade civil em relação à aceitação da diversidade étnico-racial no Brasil. Especificamente a partir do final da década de 80 e início da de 90 com a criminalização do racismo através do art. $5^{\circ}$ Inciso XLII da Constituição Brasileira, que caracterizou o mesmo como crime inafiançável e imprescritível, sujeito a pena de reclusão nos termos da lei. Durante a década de 1990 e o início dos anos 2000 ampliaram-se consideravelmente os debates e as conquistas em torno da questão das políticas de promoção da igualdade étnico-racial.

Entrando no campo do ensino nós temos no ano de 2003, durante o governo do presidente Luiz Inácio Lula da Silva, a promulgação da lei 10.639/03, o primeiro avanço no campo do ensino em âmbito federal nesse sentido. Essa lei prevê a obrigatoriedade do ensino de história e cultura afro-brasileiras em todo o currículo escolar nas escolas de nível fundamental e médio, particulares e públicas. Essa mudança do currículo se deu com o intuito de problematização do preconceito e das diversas formas de exclusão vivenciadas pelas comunidades negras na atualidade. No cumprimento desta tarefa, é dada ênfase ao ensino de história, como se coloca no $\S 2^{\circ}$ da Lei $10.639 / 2003$ : “Os conteúdos referentes à História e Cultura AfroBrasileira serão ministrados no âmbito de todo o currículo escolar, em especial nas áreas de Educação Artística e de Literatura e História Brasileiras sem prejuízo das demais" (BRASIL, 2003, grifo nosso).

A discussão da questão étnico-racial deveria se dar nas disciplinas que melhor pudessem comportar a reflexão a cerca da exclusão, cremos que essa seria razão da explicitação da história, assim como da educação artística e literatura, enquanto disciplinas escolares capazes, tendo em vista seu teor reflexivo, de proporcionar uma visão das similaridades, assim como uma compreensão de uma cultura exterior

A escola desempenha um papel formador fundamental na vida do indivíduo, devendo ser entendida como um meio social em que são vivenciadas em grande parcela pelos alunos as situações do mundo exterior, como afirma Santos (2012, p. 65):

Representando um microuniverso social, esse espaço sociocultural reflete muitos padrões de comportamento, conflitos e contradições que permeiam a sociedade em que vivemos, sendo também, poten- 
cialmente, espaço para a sua reinvenção. [...] também o preconceito e as diferentes formas de discriminação, existentes no contexto social brasileiro, integram o cotidiano escolar.

Neste contexto, a narrativa contida nos livros didáticos é um instrumento de influência na construção da memória coletiva. Esse é um dos motivos para que os poderes instituídos acompanhem de perto e com uma fiscalização rigorosa o processo de produção e difusão dessas publicações (DE LUCA, 2009, p.124). É a partir dos livros que se podem administrar as narrativas que vão legitimar os fundamentos sociais e políticos numa sociedade. Por isso, existe uma constante fiscalização dos livros didáticos, como podemos analisar no Guia do PNLD, na parte referente à história,

Os livros didáticos de História do Ensino Médio são avaliados constantemente e de modo sistemático. Você os avalia durante anos, da hora da escolha ao planejamento, do momento de capacitação ao uso com os alunos. No âmbito do PNLD, uma equipe de profissionais trabalha no mesmo sentido, durante meses, meticulosamente (GUIA DOS LIVROS DIDÁTICOS, 2014, p.12).

A educação escolar da contemporaneidade, mesmo com a influência dos meios publicitários e digitais, desempenha um papel ativo na construção da forma de perceber o mundo social. As crianças e jovens ainda passam grande parte do seu dia na escola. Marlene Cainelli em seu artigo, $O$ que se ensina e o que se aprende em história, aponta a necessidade de refletir sobre a importância do saber histórico enquanto ferramenta de formação crítica.

Os livros são fundamentalmente caracterizados como suportes didáticos, pois são usados de forma sistemática no processo de ensino aprendizagem no sentido de apreensão de determinado objeto de conhecimento. No entanto, como a sua produção fica a cargo de editoras particulares, que também tem intenção de venda externa, incorpora-se ao seu processo de produção uma característica mercadológica. Somente em 2014, o valor empregado no programa de distribuição de livros foi de 1.330.150.337, 36 de reais (PORTAL DO FNDE, 11 jul. 2015)

Célia Cassiano (2004, p. 34), vai apontar os principais aspectos que envolvem a aceitação, produção e distribuição dos livros, assim como os aspectos políticos de seu discurso, fatores chave que interferem no produto final, desde o controle do discurso, partindo do governo, e depois do crivo da editora, além da grande quantidade de profissionais que participam do processo, de forma independente do autor, dando um rumo diferente à produção.

$\mathrm{Na}$ construção dos livros, as imagens ganham cada vez mais destaque uma vez que se configuram como o veículo de comunicação da atualidade. A imagem, é um instrumento que, apesar de não ter como primeira finalidade o suporte pedagógico, pode ser, utilizada dessa forma dentro de um suplemento informativo, o livro didático. Com a mediação do professor, pode se apresentar como recurso didático na operacionalização do ensino, funcionando como um elemento demonstrativo ao entendimento de uma cultura (KOSSOY, 2001).

A preocupação com a utilização didática das imagens usadas em textos didáticos aparece em alguns desses trabalhos, que oferecem subsídios metodológicos para a análise das reproduções, em tais livros, de quadros, fotografias, charges, e demais ilustrações com suas características específicas, como no caso das legendas ou titulos que conduzem a observação do aluno (BITTENCOURT, 2004, p. 306).

Assumindo uma importância cada vez maior no aprendizado, a imagem, durante toda a segunda metade do século XX, ganhou mais do espaço reservado aos textos escritos. Etson Delegá (2012) analisa o peso dos elementos imagéticos no livro didático e o papel que cabe a esses recursos não verbais como forma, cada vez maior, de subsídio e complementação de seu conteúdo. 
Muitas vezes, a abundância de imagens compromete o conteúdo do livro.

Chegou-se ao ponto de verificar que, muitas vezes neste processo, informação é perdida, a comunicação pedagógica se desvanece, e consequentemente coloca cada vez mais nos ombros dos professores e dos próprios alunos a responsabilidade de interpretar, compreender e apreender os conteúdos (DELEGÁ, 2012).

Nesse sentido, sendo a imagem um elemento determinante na construção dos manuais didáticos, é pertinente um estudo a cerca da construção dos discursos produzidos nos livros didáticos, de uma forma geral, e no trato da história afro-brasileira de forma específica pela sua importância no processo de conscientização e combate aos diversos tipos de preconceito. Essa análise deve se realizar, tanto em relação ao à forma de inserção da imagem no texto, as legendas, tamanho, localização na página e outros critérios técnicos, mas, principalmente, nas formas de aproveitamento pedagógico. Estes são de grande pertinência por sua implicação direta na percepção dos conteúdos históricos pelos educandos. A pesquisa teve como objetivo o mapeamento de todas as coleções de livros aprovadas pelo Plano Nacional do Livro Didático (PNLD - 2012), com vistas a estabelecer, em consonância com a lei $n^{\circ}$ 10.639/03, um perfil geral de como o negro é retratado nas publicações didáticas de história através das imagens que se referem à história afro-brasileira. $\mathrm{O}$ presente artigo se propõe a anunciar as primeiras conclusões a cerca do acervo iconográfico dos livros.

O primeiro procedimento realizado foi um levantamento bibliográfico para a interação com as principais discussões a respeito da temática, sabendo-se já do grande volume de produções que tem o livro didático como objeto de estudo. O segundo passo se deu com a elaboração de um banco de dados para a catalogação das imagens em formato de planilha no programa $\mathrm{Mi}$ - crosoft Excel. A tabela conta com os seguintes elementos de identificação: referência da coleção (da ABNT): capítulo, subcapítulo, seção, página; os dados de tipologia: título da imagem, legenda, autor, ano, acervo/fonte, e observações gerais.

No processo de catalogação e análise das imagens no período da pesquisa foram consideradas nove das dezenove coleções constantes no Plano Nacional do Livro Didático de 2012. A catalogação feita resultou em um quantitativo de 455 imagens encontradas nos livros de História Geral e do Brasil. No entanto, tendo em vista o gigantismo do trabalho, optou-se pela continuidade somente com aquelas imagens que relacionam a história da África com o Brasil, totalizadas em 313.

\section{O problema das legendas}

Uma primeira questão a ser colocada é de padronização das legendas. Entendemos por legenda, para os fins da pesquisa, o enunciado que, vindo de forma conjunta à imagem, não só a referencia, mas também a explica, sendo muitas vezes responsável por sua inserção ao texto. Como coloca SANTOS (2005, p. 1091): é dizer "o que não se vê, a partir do que se vê". É um elemento fundamental para a compreensão das imagens, uma vez que elas fornecem dados que remetem a sua temporalidade - como título, autor, ano, e ajudam a explicar a imagem, assim como para a sua utilização pedagógica.

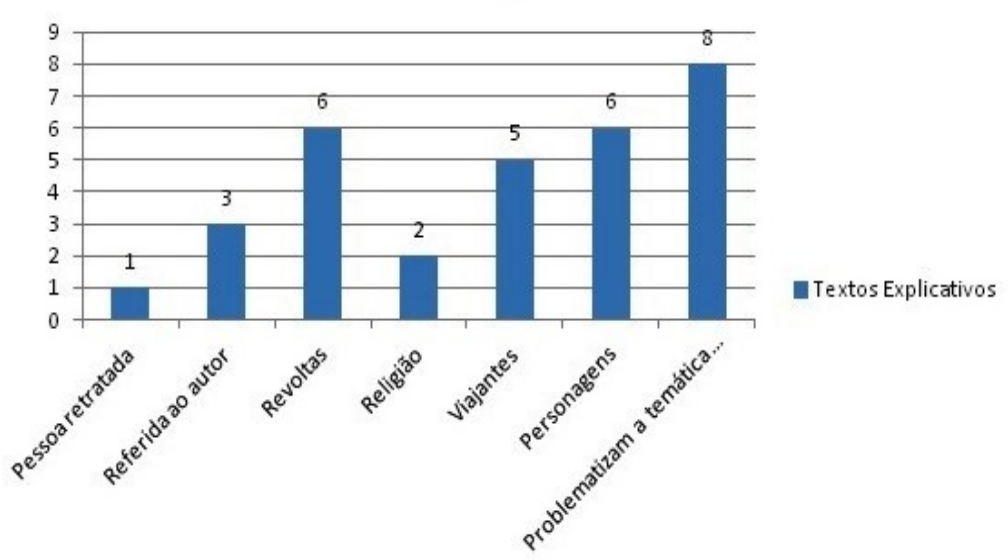

Imagem 1-Divisão Temática das imagens em que foram encontrados textos explicativo. 
Do total de imagens, somente 23, estão relacionadas a textos explicativos. Desse total podemos subdividir em textos ligados diretamente a biografia dos retratados, textos associados a séries de imagens que têm como objetivo ressaltar determinado episódio histórico de protagonismo negro, personagens históricos que os livros consideraram relevantes, ligados às impressões que do Brasil pelos viajantes que por aqui passaram. As formas de manifestação religiosas e também ligadas às pessoas retratadas nas imagens. Em grande parte das imagens realizadas existem explicações a cerca do seu conteúdo dentro das próprias legendas dado não quantificado para esta publicação.

Nos livros observados, embora tenha sido vista essa preocupação com a contextualização nas legendas, ela não foi feita de forma eficaz, como se pode ver em alguns dados do gráfico a seguir:

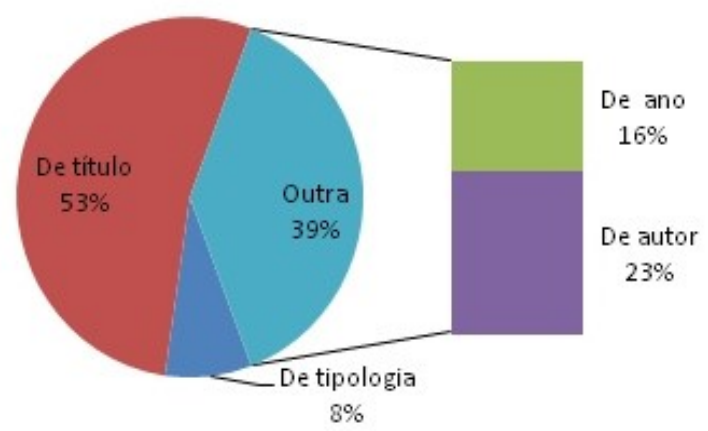

Imagem 2-Parcela das Imagens que apresentam lacunas quanto a informações referenciais.

Nas 313 imagens analisadas para história afrobrasileira, notou-se não só uma falta de preocupação com as legendas em 137 (44\%). Outra lacuna inicialmente percebida foi à carência de informações fundamentais ao entendimento das imagens como os títulos, por exemplo, que não foram vistos em 165 $(53 \%)$ das imagens analisadas, sendo seguidos pela ausência de autor 184 (23\%) e de datação 50 (16\%).
Percebeu-se uma carência também nas de informação nas fotografias mais modernas provenientes de bases eletrônicas online, constando nas referências apenas o nome do autor e da base eletrônica de onde foram tiradas Em algumas imagens existe uma parcela minoritária das coleções que referência os vários locais onde a imagem existe, ficando em primeiro lugar os acervos nos quais estão os originais e, depois, quando existem (porque muitas vezes é retirado de uma base de imagens da própria editora), aqueles de onde elas foram retiradas para compor a publicação. Nas imagens mais antigas, como as do início do período colonial, constata -se esse problema de uma forma mais atenuada, com uma falta dos títulos reais das mesmas, havendo apenas uma referencia ao que está sendo retratado.

\section{Da predominância do tema escravidão}

Outro ponto percebido na catalogação das imagens dos livros didáticos foi à predominância do tema escravidão na maioria das imagens analisadas. Essa predominância de imagens que tem como objeto o período colonial brasileiro e fazem uma correlação da escravidão com os diversos aspectos da sociabilidade daquela época nos quais o escravo estava inserido.

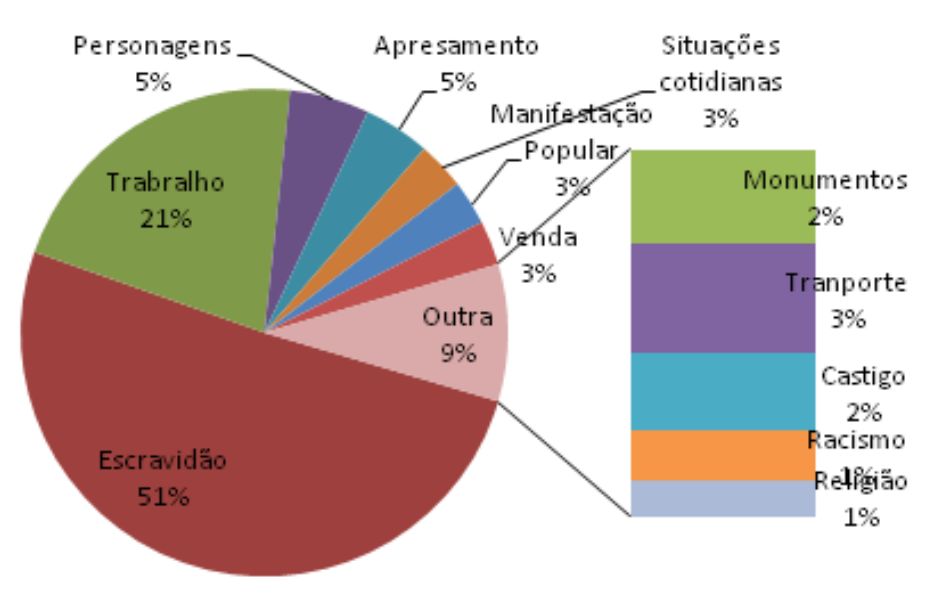

Imagem 3-Quanto à presença do motivo escravidão nas imagens, e seus desdobramentos temáticos.

Podemos ver no gráfico, que 159 (51\%) das imagens analisadas têm como objeto a escravidão, e também que esse quantitativo se desmembra em vários 
temas, trabalho $65(21 \%)$, personagens $15(5 \%)$, situações cotidianas $9(3 \%)$ manifestações populares 9 $(3 \%)$, venda $9(3 \%)$ e outras $27(9 \%)$, relacionada à escravidão, essa presença se dá de forma meramente ilustrativa ao conteúdo curricular, não havendo nessas imagens uma contextualização para debate de temáticas cotidianas, que deram motivação a lei 10.639/03, como por exemplo o racismo.

Nas imagens abordadas identificamos a escravidão como um grande tema, e o trabalho como o principal foco deste, outros aspectos da vida dos escravizados são vistos com uma menor ênfase. Uma vez que na grande maioria das imagens contidas nas coleções não têm um motivo único, muitas das quantificadas em mais de um item do gráfico. Reafirmamos uma abordagem clássica do currículo europeu, uma vez que a maioria das imagens adota a temática da escravidão negra de acordo com os marcos temporais da historiografia europeia.

Sobre esta parcela de imagens é pertinente colocar que em sua maioria se tratam de fotografias ou imagens construídas virtualmente e constantes em bases iconográficas virtuais. Existe um quantitativo maior de que aborda o século XIX, assim como uma variedade maior quanto à tipologia e motivos nesse período temporal, isso se deve a vários fatores. O primeiro deles pode ser colocado como a existência da fotografia, o invento descoberto em 1839 proporcionou uma maior profusão de imagens.

Pátria da luz, morada do sol, o Brasil conheceu muito cedo a invenção de Daguerre, poucos meses depois do anúncio oficial de sua invenção, feito em Paris a 19 de gosto de 1839. Com efeito, já a 17 de janeiro de 1840 o abade francês Louis Compte, capelão da fragata L'Orientale, tirou os primeiros daguerreótipos em território brasileiro (VASQUEZ, 2002, p. 8).

O cineasta Pedro Karp Vasquez em seu livro, A Fotografia no Império vai reconstruir o processo de difusão da fotografia no Brasil através da chegada do navio L'Orientale vindo da França. O próprio imperado Dom Pedro II vai ser um grande favorecedor da sua difusão, sendo ele um dos primeiros compradores da máquina no Brasil, além ter registrado uma grande quantidade de imagens.

O segundo fator seria um grande número de acontecimentos históricos significativos à História do Brasil ocorridos na segunda metade do século XIX que sendo integrantes do currículo, tem larga representação nos livros, como, por exemplo, a abolição da escravidão, vinda dos imigrantes, revoltas e escravos, crítica ao processo de abolição na imprensa. A sua segunda metade é o palco de eventos e circulação de ideia que são de vital importância para o entendimento e a estruturação da sociedade brasileira na contemporaneidade, do ponto de vista da aceitação da diversidade étnica.

Existiam duas correntes de ideias conflitantes, de um lado havia a visão da mestiçagem enquanto causa de degeneração mental e social, de outro, existia um fluxo de ideias que falava que a diversidade genética favorecia a adaptação dos indivíduos ao meio, gerando seres mais fortes. Devido a diversos fatores de cunho social e econômico (necessidade de aumento de consumidores do mercado europeu), tanto as ideias, quanto as estruturas que davam base ao modelo escravocrata estavam sendo desmontadas. As teorias raciais vindas da Europa ganhavam adeptos nos mais altos estratos sociais e intelectuais da sociedade brasileira. De forma geral era consenso à ideia de superioridade genética da "raça branca" e que esta, através da miscigenação suplantaria a "negra", responsável por uma grande degenerescência cognitiva e social na população brasileira.

Simultaneamente a difusão das teorias que defendiam o aumento da miscigenação como fator de 
degenerescência genética, temos a difusão das ideias do darwinismo social no Brasil. Essa corrente ia à contramão das teorias raciais entendendo a miscigenação como um fator positivo de adaptação, fusão de tipos genéticos. No entanto pode se entender a questão da perpetuação do pensamento racializante no Brasil como um marco de distinção social, substituindo a escravidão (SCHWARTZ, 1993, p. 24).

No tema do trabalho, a iconografia aborda predominantemente o trabalho rural, primeiro nos engenhos de açúcar e depois no cultivo de algodão e café. A majoritária das imagens se refere ao trabalho nas lavouras de café em razão do contexto histórico no final do século XIX, onde o produto era largamente exportado e á certa crise causada pela diminuição do número de escravos. A produção agrícola voltada para a exportação, visando o mercado europeu era uma característica do modelo de produção brasileiro à época. A iconografia aborda a substituição do trabalho escravo pela mão de obra imigrante.

Existia uma preocupação, da elite intelectual e política do Brasil, desde o início do século XIX com o lugar que seria ocupado pelos negros no país. Existia um clima internacional de descontentamento com a condição de escravidão, essa conjuntura pode ser verificada através da explosão de revoltas de libertação dos escravos por muitos locais do mundo como na segunda metade do século XIX, como por exemplo, Suriname, São Domingos, Jamaica, Haiti e outros.

A substituição da mão de obra escrava pela imigrante já era considerada como alternativa à manutenção da mão de obra. . A legitimação desse processo se deu através da construção de um discurso de incapacidade dos negros para o trabalho dentro da dinâmica do capitalismo e sua posterior marginalização. Foi verificada de forma pouco no discurso da iconografia das coleções a problematização dessa passagem
(AZEVEDO, 2004b).

No que diz respeito aos personagens, a sua inclusão nos manuais didáticos não é recente, mas data do século XIX, e sua motivação.

\section{Menções positivas a personagens históri-} cos afrodescendentes já podem ser localizadas no primeiro livro didático de história do Brasil, o Compêndio de história do Brasil (1843), de José Inácio de Abreu e Lima. [...] Essa presença descortina uma faceta antiescravista e antirracista, mas não abolicionista, do pensamento historiográfico do periodo (2009, p. 300).

Com uma base nas ideias liberais e iluministas, "a lição a ser ensinada era de que a cor não passaria de um "acidente", como a "glória" e a coragem dos heróis citados bem comprovariam" (MATTOS, 2009, p.300).. A historiadora Circe Bittencourt coloca que o final do século XIX e o início do XX foi palco da difusão de ideologias como o mito das três raças dentro das publicações didáticas. Essa foi uma característica da historiografia nas décadas finais do século XIX, a invenção da nacionalidade (BITTENCOURT, 2011, p. 60).

Outra representação recorrente na iconografia didática é o Zumbi dos Palmares. Esse líder abolicionista é representado tanto de forma parca na iconografia do século XIX, como em monumentos contemporâneos quando se aborda o combate ao racismo. Existe um diálogo entre a representação clássica e a significação contemporânea. "Decerto, essa perspectiva se relaciona ao fortalecimento, na década de 1970, do movimento negro, que, desde então, investiu na figura de Zumbi como ícone da denúncia do racismo, e da sua proposta de resistência e libertação" (MATTOS, 2009, p. 303).

As situações cotidianas que não estavam diretamente relacionadas ao trabalho como as festas, hábitos e demais manifestações populares dos cativos, reflexo de um currículo permeado por uma ótica europeia da História onde tanto os marcos processuais quanto seus fatos de referencia, mesmo o tráfico de escravos tem 
uma iconografia inexpressiva em relação as modalidades de trabalho. Uma constatação geral a de que essa iconografia não foi utilizada de forma eficaz no sentido da problematização em relação ao racismo e aos diversos tipos de preconceito.

\section{Reflexões a cerca do conteúdo}

É inegável, considerando o ambiente de abundante produção de imagens em que vivemos na contemporaneidade, a eficácia do documento visual na ilustração para o entendimento de determinada realidade, a importância dada ao estudo do elemento visual aconteceu em várias áreas do conhecimento, como defende Meneses (2012):

Assim, a contribuição de antropólogos e sociólogos, antes e depois da consolidação institucional de seus quadros de trabalho, foi sensivel e ampla em algumas frentes, quer ressaltando o potencial cognitivo do documento visual quer valorizando a dimensão visual da vida social quer, enfim, propiciando a substituição de um padrão epistêmico observacional por outro, discursivo (MENESES, 2003, p.19, grifo nosso).

$\mathrm{Na}$ utilização pelos historiadores, o potencial cognitivo das imagens, precisa ser devidamente direcionado, uma vez que o fim da exploração dos documentos icônicos no caso do fim pedagógico é completamente diferente, pois ele

\section{[...] já possui um conhecimento histórico sobre o perídodo e tem o domínio de conceitos e categorias fundamentais para a análise histórica. Ao usar um documento transformado em fonte de pesquisa, o historiador parte, portanto, de referências e de objetivos muito diferentes aos de uma situação em sala de aula (BITTENCOURT, 2004, p.329).}

Os jovens não compreendem os documentos iconográficos com a mesma visão do historiador, eles não têm um propósito de pesquisa e não possuem formados previamente aqueles conceitos necessários para a apreensão dos significados contidos nas imagens (BITTENCOURT, 2004). No entanto, se feito com uma orientação metodológica pertinente, o uso dos documentos, apesar dos mesmos não terem sido feitos para esse fim, pode servir:

[...] para introduzir o tema de estudo,
assumindo, nesse caso, a condição de
situação-problema, para que o aluno
identifique o objeto de estudo ou o tema
histórico a ser pesquisado. Dessa forma,
os objetivos dos documentos são bastante
diversos para o professor e para o
historiador, assim como os problemas a
que ambos fazem frente (BITTENCOURT, 2004, p. 329).

O foco para a utilização pedagógica pelo professor seria então a visualização pelo aluno de determinada realidade, assim como o assessoramento a discussão de determinados conceitos, como, no caso da temática afro -brasileira, o racismo, a exclusão social, entre outros. Embora a discussão do racismo já se dê de forma enraizada, no decorrer das coleções, as referências, em sua maioria, fazem alusão ao período escravista, como anteriormente citado por Hebe Mattos (2009, p. 309):

A escravidão e seu periodo respectivo
tornam-se passados que parecem não
querer passar. Como os os
afrodescendentes são quase que
exclusivamente associados ao trabalho
escravo e formação da chamada cultura
brasileira mestiça no periodo colonial, à
formação da chamada cultura brasileira
mestiça no período colonial, isso quase
inviabiliza, nos livros analisados, o
reconhecimento do protagonismo politico
desses sujeitos sociais para além da luta
com os seus senhores.

Quanto às legendas, a carência de informações inviabiliza tanto um maior conhecimento a cerca da imagem quanto uma maior contextualização com o conteúdo e utilização pedagógica. A forma como a legenda é colocada pode alterar o significado da imagem, direcionar a visão para determinado elemento icônico ou artístico. Desse modo a importância fundamental da legenda no processo de utilização 
pedagógica das imagens (LUSVARGHI; ZARATTINI, 2012).

Nas fotografias vemos esse problema de forma mais gritante, principalmente naquelas tiradas por fotógrafos de destaque não tão grande. As bases eletrônicas não apresentam referências claras sobre a maioria das imagens, nos livros não vemos uma preocupação de esclarecimento nesse sentido, o que deixa uma lacuna no sentido de que a fotografia fica desprovida do seu referencial que permite captar a visão do autor, como compreende Benjamin (1938) a natureza da fotografia vai além do ambiente trabalhado racionalmente pelo autor, é um retrato, digamos assim, imediato do ambiente escolhido por ele o seu "inconsciente ótico", além de sua interação com os modelos, quanto eles existem na fotografia. Não fornecer dados sobre o fotógrafo seria, portanto, comprometer a relação entre texto e imagem.

Quanto à relação da quantidade de fotografias que trata da escravidão e uma ausência da contextualização dessas com o toda esta é uma deficiência que foi vista em edições anteriores dos livros didáticos aprovados. Em Personagens negros em livros didáticos: reflexões sobre a ação política dos afrodescendentes e as representações da cultura brasileira, onde vai procurar historicizar a presença dos grandes personagens negros nos materiais didáticos brasileiros, é o que percebe Mattos (2005) quando faz uma análise de duas coleções de 2002 e 2005, respectivamente, a coleção História Temática, de Montellato, Cabrini e Catelli, pela editora Scipione, e História e vida integrada, de Nelson Pilletti e Claudino
Pilletti, e enxergar nelas o mesmo problema da avaliação apresentada.

No decorrer da pesquisa de análise em nove das dezenove coleções que compõem o PNLD 2012 foram analisadas 313 imagens que, obedecendo à proposta da pesquisa, tinham como objeto da história do Brasil. Vimos primeiramente, que grande maioria das imagens não estava referenciada de forma correta e expusemos a importância das legendas na utilização das imagens como instrumento didático. Identificamos também que somente uma minoria das imagens citadas era aproveitada para exercícios de forma mais direta, além de identificar, no que diz respeito aos temas tratados nas imagens, uma predominância da escravidão e um desmembramento desta em subtemas, com uma deficiência de diálogo entre os períodos históricos, o que propiciaria um debate mais consistente sobre a temática do racismo, que existe, só que de forma mais reduzida.

Problematizar a produção dos livros de história, no que diz respeito não somente a iconografia, mas nos seus aspectos, comercial, político e físico ainda é um nicho relativamente novo para os historiadores. Além de todos os elementos de avaliação que já pesam sobre o $\mathrm{PNLD}^{1}$. A crítica constante em torno do livro didático, que, embora não possa atender a uma ambição do "livro perfeito", onde todas as carências sejam supridas, é fundamental para manter as discussões desse valioso instrumento, muitas vezes, o único a que o aluno tem acesso como fonte de um conhecimento pedagogicamente orientado.

\footnotetext{
${ }^{1}$ Ver Guia do Plano Nacional do Livro Didático. 2012. Disponível em : $\quad<$ http://portal.mec.gov.br/index.php? option=com_content\&view=article\&id=12389:guias-do-livro-didatico\&catid=318:pnld\&Itemid=1129>. Acesso em 10 jul 2015.
} 


\section{Referências bibliográficas}

AZEVEDO, Janete Maria Lins de. A Educação como política pública. $3^{\mathrm{a}}$ Ed. São Paulo: Autores Associados, 2004a.

BARBOSA, Cibele. Implantação do Laboratório Acervos e Material Didático (Labdidática). Fundação Joaquim Nabuco. Recife: 2013.

BRASIL. Conselho Nacional de Educação. Resolução n 1 de 17 de junho de 2004b. Institui Diretrizes Curriculares Nacionais para a Educação das Relações Étnico-Raciais e para o Ensino de História e Cultura Afro-Brasileira e Africana. Disponível em: <http://portal.mec.gov.br/cne/arquivos/pdf/003.pdf>. Acesso em: 21 out. 2015.

BITTENCOURT, Circe Maria. Livros e Materiais Didáticos de História. In: Ensino de história: fundamentos e métodos. São Paulo: Cortez, 2004.

CAINELLI, Marlene. O que se ensina e o que se aprende em história. In: OLIVEIRA, Maria Margarida Dias de (Coord.) Coleção explorando o ensino: História. Vol.21. Brasília: Ministério da Educação, Secretaria de Educação Básica, 2010.

DE LUCA, Tânia Regina. O livro didático de história hoje: um panorama a partir do PNLD. Revista Brasileira de História, vol. 24, n $48,2009$.

DELEGÁ, Etson. O Papel da Imagem no Livro Didático. Disponível em: <https://www.google.com.br/url? $\mathrm{sa}=\mathrm{t} \& \mathrm{rct}=\mathrm{j} \& \mathrm{q}=\& \mathrm{esrc}=\mathrm{s} \&$ source $=$ web $\& \mathrm{~cd}=1 \& \mathrm{ca} \quad \mathrm{d}=\mathrm{rja} \& u a c t=8 \& \mathrm{sqi}=2 \& v e d=0 \mathrm{CB} 0 \mathrm{QFjAA} \& u r l=\mathrm{http} \% 3 \mathrm{~A} \% 2 \mathrm{~F} \%$ 2Fwww.jornaldaeducacao.inf.br\%2Findex.php\%3Foption\%3Dcom_content $\% 26 \operatorname{task} \% 3$ Dview\%26id $\%$ 3D1725\&ei=1BqbVfqhGYWzggSCkIoDw\&usg=AFQjCNGeW5U91BxGqOOBtFlZue1qGuixQ\&sig2=rubknZa WKCP9Uik6NeUKaw\&bvm=bv.96952980,d.eXY>. Acesso em: 6 jul. 2015.

Guia dos livros didáticos: PNLD 2015: História: ensino médio. Brasília: Ministério da Educação, Secretaria de Educação Básica, 2014.

KOSSOY, Boris. Fotografia e História. $2^{\circ}$ ed. São Paulo: Ateliê Editorial, 2001. LIBÂNEO, José Carlos. Didática. São Paulo: Cortez, 2009.

LUSVARGHI, Luiza; ZARATTINI, Mônica. A função normativa da legenda fotográfica: o massacre de Realengo. Discurso Fotográfico, v. 8, n.12, 2012, p. 54-78.

MATTOS, Hebe et al. Personagens negros e livros didáticos: reflexões sobre a ação política dos afrodescendentes e as representações da cultura brasileira. In: ROCHA, Helenice Aparecida Bastos et al. (Org.). A história na escola: autores, livros e leituras. Rio de Janeiro: Editora FGV, 2009.

MENESES, Ulpiano T. Bezerra de. Fontes visuais, cultura visual, história visual: balanço provisório, propostas cautelares. Rev. Bras. Hist. 2003, vol.23, n.45, pp. 11-36.MOTTA-ROTH, Desirée; HENDGES, Graciela Rabuske. Produção textual na universidade. São Paulo: Parábola Editorial, 2010.

MOCELIN, Renato; CAMARGO, Rosiane de. História em Debate. 2 ed. voll. São Paulo: Editora do Brasil, 2010. PEDRO, Antônio; LIMA, Lizânias de Souza. História sempre presente.1º ed. Vol. 2. São Paulo: FTD, 2010.p.372.

ROCHA, Helenice Aparecida Bastos et al. (Org.). A história na escola: autores, livros e leituras. Rio de Janeiro: Editora FGV, 2009.

SANTOS, Milton. O professor como intelectual na sociedade contemporânea. Conferência de Abertura do IX ENCONTRO NACIONAL DE DIDÁTICA E PRÁTICA DE ENSINO, realizado em Águas de Lindóia - SP, de 4 a 8 de maio de 1998.

VAINFAS, Ronaldo; SILVA dos Santos, Georgina; FERREIRA, Jorge Luiz; SIQUEIRA de Castro Faria. Sheila. História: o longo século XIX. São Paulo: Saraiva, 2010. 